\title{
The Concept of an Interactive Platform for Real Time Energy Consumption Analysis in a Complex Urban Environment
}

\author{
Ales Podgornik $^{* 1}$, Boris Sucic ${ }^{1}$, Ljubisa Urosevic ${ }^{2}$ \\ ${ }^{1}$ Energy Efficiency Centre, Jozef Stefan Institute, Ljubljana, Slovenia \\ e-mail: ales.podgornik@ijs.si \\ ${ }^{2}$ ATB - Institut für angewandte Systemtechnik Bremen GmbH, Bremen, Germany
}

Cite as: Podgornik, A., Sucic, B., Urosevic, Lj., The Concept of an Interactive Platform for Real Time Energy

Consumption Analysis in a Complex Urban Environment, J. sustain. dev. energy water environ. syst., 3(1), pp 79-94 2015, DOI: http://dx.doi.org/10.13044/j.sdewes.2015.03.0006

\begin{abstract}
This paper presents the concept of an interactive and comprehensive platform based on an advanced metering infrastructure for exchanging information on energy consumption (and consequently on energy efficiency) in an urban and industrial environment which can serve as a powerful tool for monitoring progress in the transition toward a low carbon society. The proposed concept aims at supporting energy utilities in optimizing the energy performance of both supply and demand side aspects of their work and has the potential to fill a gap and help in harmonization of interests between the energy utilities, energy service providers, local energy agencies and citizens. The proposed concept should be realized as a platform with modular architecture, allowing future expansion of the user's portfolio and inventory management (new energy efficiency measures, technologies, different industries, urban districts and regions).
\end{abstract}

\section{KEYWORDS}

Energy efficiency, Smart metering, Consumption feedback, Energy behaviour, Sustainable development, Energy utility.

\section{INTRODUCTION}

The transition toward a low carbon society has become a primary climate mitigation activity in many countries. Success in achieving this goal will largely depend on promoting efficient energy end-use in urban and industrial environments. Several studies have confirmed that the decisions and concrete actions of individuals have to be considered in the effort to impact end-user energy behaviour as they can have greater power and effect than the ability of the municipal administration to direct in their actions $[1,2]$. The end-user's behaviour is a very important parameter for the success of every national energy efficiency policy and related programmes. Many contemporary policies and instruments for achieving energy savings potential are mainly oriented to technical systems (building envelope, heating systems, electrical appliances), while behavioural changes are addressed only by the improved availability of information through awareness campaigns [3,4]. According to [5], user behaviour is at least as important as building physics when it comes to energy consumption for heating, while electricity consumption for lighting and appliances is more dependent on user behaviour than on energy efficiency of appliances. Also, several studies have clearly confirmed that user behaviour can be influenced and different models can be used for explaining why and how feedback on electricity consumption can reduce consumption [5-7].

\footnotetext{
* Corresponding author
} 
In the framework of sustainable and climate-friendly development of the urban environment, two often highlighted problems are an efficient and secure energy supply and efficient spatial planning. Recent developments in energy system planning focus on considering various $\mathrm{CO}_{2}$ reduction scenarios in order to reach set goals $[8,9]$. Development of electricity smart grids is recognised as an important element in the process of transformation towards new and low carbon energy systems [10]. However, electricity smart grids must be coordinated with the utilisation of renewable energy sources (RES) being converted into other forms of carriers, than electricity including heat and biofuels, as well as energy conservation and efficiency improvements [11]. Also, future decisions should be made on the basis of a systematic techno-economic analysis using local energy supply chain models and not a-priori favouring any particular development option [12]. Also, the local component of policy implementation is mandatory to achieve results on a national level [13]. In a complex urban or industrial environment change authorities (legal entities identified by others as key promoters and supporters of change) could be the energy utilities, with their technical background and excellent understanding of energy and environmental aspects which are needed for the future sustainable development of a smart urban environment. However, the energy utilities need innovative energy efficiency approaches based on a comprehensive knowledge of alternative possibilities of development, and especially an awareness of new opportunities in exploitation of the urban and industrial environment as an energy system utilizing RES and other smart grid-enabled services integrated in an intelligent knowledge infrastructure [14]. According to [15], incorporation of such intelligence and other advanced components can be employed in a modelling approach in which the urban environment is covered by energy consumption and production nodes connected together by energy networks which enable spatial energy flows. The challenge of integrating RES into electricity grids cannot be looked upon as an isolated issue, but should be seen as one of the various means and challenges of achieving sustainable energy systems in Europe [11]. Therefore, the integration of renewable energy into the electricity sector must be coordinated with other sectors such as heat supply and transportation, as well as energy conservation and efficiency improvements. There is a need for a system-level approach to integrate the smart grid components into coherent systems in such a way that energy policy goals and market profitability are ensured and in line with the notions of efficiency, conservation and sustainability [16].

Currently, energy utilities provide their customers information on their energy consumption only on a monthly or even two-monthly basis. The information provided by smart meters is used by utilities for various monitoring and control purposes on the supply side and monthly billing according to actual consumption. Unfortunately, this new information is not used for the optimization of the energy system, implementation of advanced local energy management, or to enable greater adoption of energy efficiency measures on the demand side. Experimental results have already shown the advantages of advanced local energy management through a building-integrated microgrid coupled with photovoltaic (PV) systems for a power balancing strategy with smart grid interactions and facilitation of grid scale optimization $[17,18]$. Smart metering adds value to the ordinary utility service, giving better information to consumers and optimizing the use of the demanded power and consumed energy [19]. It implies a new relational model between the utility and its clients, using Information and Communication Technologies (ICT) to interchange information between the utility and the devices installed at the consumer's premises. One of the limitations of existing models is the use of low-resolution consumption data where temporal variations of energy consumption are not covered [20]. This new information on energy efficiency 
represents a significant potential to support decisions in the scope of maximizing energy savings and consequently minimizing $\mathrm{CO}_{2}$ emissions, especially as the majority of people tend not to see or feel the link between their actions (behaviour) and their energy performance and its impact on the environment. According to [21], environmentally relevant behaviour refers to any behaviour that can be identified as having a significant direct or indirect impact, negative or positive, on the health and stability of natural (eco)systems. Since there is a direct link between energy consumption and the environmental impact of that consumption, it can be concluded that energy-relevant behaviour is a subset of environmentally-relevant behaviour. Behavioural aspects and the social context for residential end-users have to be taken into account more in product and service development to ensure the adoption of smart products and services [2, 21]. Successful strategies for consumer engagement need to be focused on building trust and confidence among consumers [22]. However, there is a need for a system that will provide higher-quality, more detailed and contextualized information about energy consumption on a more frequent basis, and a system with the capacity to analyse the information received and act on the parameters available in real-time to correct possible dysfunctions in energy use and inform (alarm) the end-user.

This paper presents the concept of an interactive and comprehensive platform for energy consumption analysis and exchange of information on energy efficiency in urban and industrial areas. The use of this additional information should enable the creation of a high resolution image of energy consumption and build a complete energy profile in the different end-user environments (industrial companies, public buildings and households). The proposed concept also aims at supporting utilities in optimizing the energy performance of both supply and demand side aspects of their work. It could serve as powerful tool for monitoring progress in transition toward a low carbon society. The proposed concept of an interactive platform has the potential to fill the gap and help in harmonization of interests between the energy utilities, energy service providers, local energy agencies and citizens and can represent the first and necessary step in the development of a smart urban environment. Further, an important objective of the proposed concept is to enable a positive 'it can be done attitude' and confidence building between energy utilities and final consumers.

\section{METHODOLOGY - INTERACTIVE PLATFORM CONCEPT}

Understanding different forms of pro-environmental behaviours rest on different models which consist of different factors (dependent and independent variables). Purpose of models is to explain relationships among variables and to present them in a parsimonious way. The proposed concept is based on continuous consumption monitoring and new algorithms for identification and analysis of end-users' energy consumption patterns. It should be realized as a platform with modular architecture in the form of a set of ICT building blocks. This would allow future expansion of the user's portfolio and inventory management (new measures, technologies, different industries and public buildings, urban districts and regions). The data used for identification of the energy consumption patterns should also be used for extraction of the energy consumption context. An important component of this extracted context should be end-user behaviour. The platform should enable the following:

- Gathering real time energy consumption data at 1 minute intervals in the case of electricity, and at 1 hour intervals in the case of heat;

- Analysis and contextualization of energy consumption (including benchmarking);

- Providing a knowledge sharing system for communicating results and requests between energy utilities and end-users. 
Reviewers of European smart grid projects revealed a strong focus on observation, highlighting the widespread need to increase knowledge of consumers, to understand their reactions and the drivers of their behaviour [22]. While many projects have tried to involve consumers by providing them with information, fewer have reached the stage of investigating the ways to best present this information to the consumer and of actively developing social marketing strategies for consumer engagement. To overcome these barriers, the proposed concept must include effective communication between the energy utility and final customers with the emphasis on reception of real-time data from intelligent metering systems. The incorporation of a pervasive monitoring and communication infrastructure is essential in smart grids to measure the system state, propagate the control signals and allow distributed smart applications to control power flows $[22,23]$. The innovative set of building blocks will allow the identification of energy profiles and energy consumption patterns and their interrelations to support energy efficiency optimization and $\mathrm{CO}_{2}$ emissions reduction, using the combination of knowledge management and smart metering technology for innovative data/information/knowledge processing. These profiles and patterns can then further support the decision-making process in three different contexts (see Figure 1):

- The utility adapts its services, Demand Side Management (DSM) and Demand Response Services (DRS) to the real energy use conditions of end-users for efficient local balancing and reduction of the supply power needed on the end-user side;

- Smart integration of de-centralized renewable energy production, Combined Heat and Power (CHP) units, and trigeneration systems (or Combined Cooling, Heat and Power - CCHP) as local supply support points for efficient local balancing and maximizing the utilization of RES. In addition to this, a result of the proposed concept could be optimized spatial planning (district heating and cooling) for efficient use of municipality resources and exploring the potential of using Cool Thermal Energy Storage (CTES);

- Individualized and contextualized consumption feedback used to stimulate the conscious decisions of end-users and development of new energy efficient habits, including detection of energy consumption leakages and other consumption deviations. This approach is based on the goal setting strategy (e.g. to reduce energy consumption by $10 \%$ ) for promotion of pro-environmental behaviour and energy efficiency. The main assumption is that goal setting on group level in combination with supportive social environments and rewards for successful households can be successful strategy for triggering sustainable behavioural changes.

The proposed concept comprises five interlinked functionalities with the following features:

- End-user consumption data acquisition: interconnection with smart meters, where consumption data is acquired at 1 minute intervals in the case of electricity, or 1 hour intervals in the case of heat, which should enable development of pattern recognition algorithms;

- Pattern recognition algorithms: discovering patterns of energy and appliance usage to identify unnecessary consumption, to find opportunities for change, and to set targets for improvement;

- Context-sensitive processing: enriching the consumption data with information already stored in the knowledge repository of the utility (location, end-user profile, current use/ installation of de-centralized renewable energy sources and CHP, etc.);

- Consumption feedback: elaborate individual energy profiles (combining individual end-user data) to contextualize consumption feedback (benchmarking, awareness raising, warnings and alarming). This includes communicating information about 
energy consumption effectively to the end-user to increase awareness of the relevance of one's behaviour to energy consumption, and awareness of one's possibilities to influence personal behaviour;

- Decision support services: introducing end-user energy consumption profiles and end-user behavioural parameters on the principles of Game Theory into the utility decision process to support the utility's DSM centre and DRS. This enables harmonization of interests between utilities (as service providers) and end-users, together with local balancing and local supply integration (de-centralized renewable energy production and CHP, etc.) in the complex urban and industrial environment.

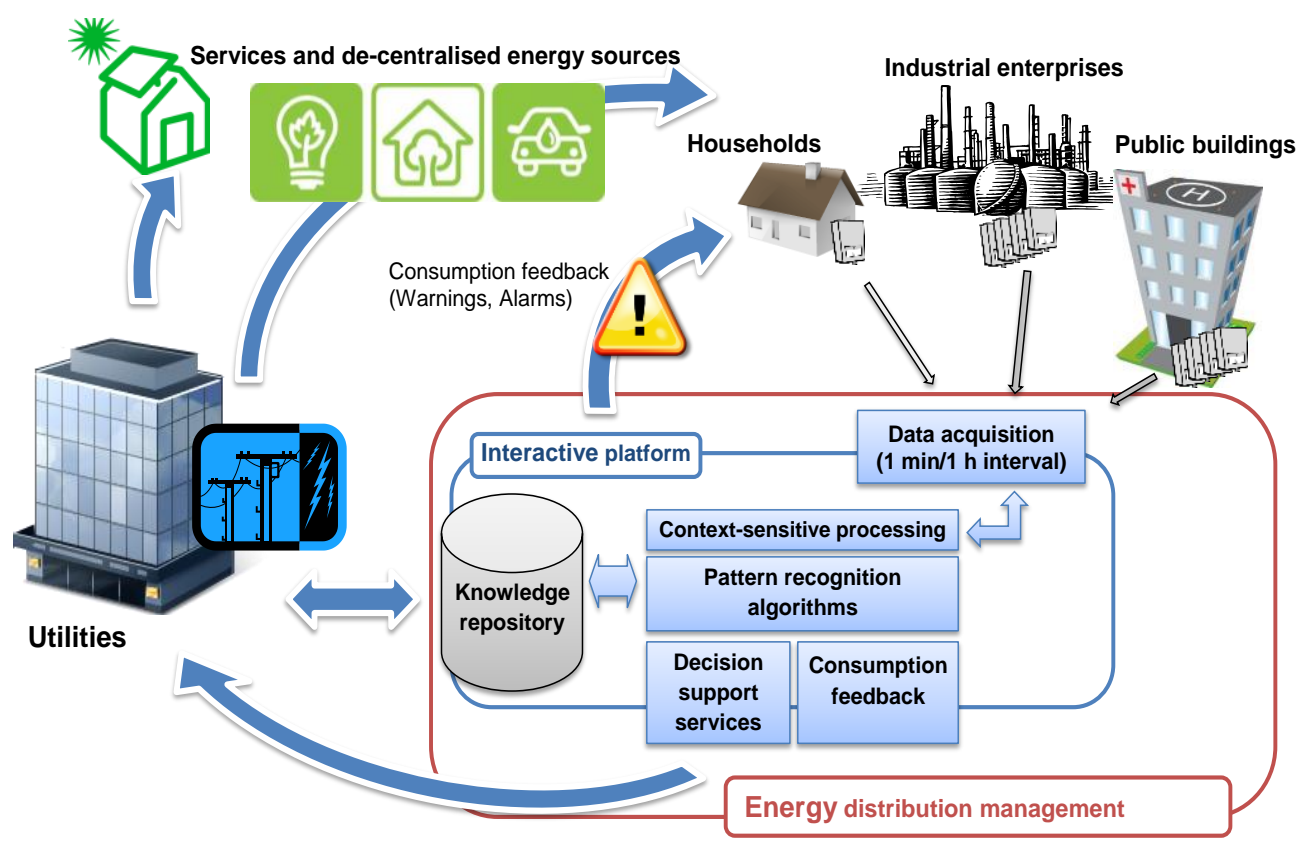

Figure 1. Schematic view of the proposed concept of an interactive platform to support sustainable development of energy utilities

\section{End-user consumption data acquisition and pattern recognition}

The detailed electricity load profile of a domestic or industrial electricity consumer is an important requirement for the accurate analysis of DSM. For example, the use of electrical appliances within households varies significantly in time, mainly in accordance with the activity and behaviour of the occupants. The highest resolution time information available on electricity consumption in real-life grids is every 15 minutes, which is the measurement interval for load profile analysis in an industrial environment. This resolution is adequate to show variations in consumption and is used for billing. Figure 2 shows an example of electricity consumption recorded at three different time intervals in a real-world industrial environment - a container-handling gantry crane load profile.

The daily load profile logged at 1 minute intervals can provide more useful information about the influence of end-user behaviour on electricity consumption and its response to DSM signals. For example, where DSM is driven by electricity price changes, the utility needs to understand and predict customers' response to this change, but a high resolution image of electricity consumption is necessary. It is clear that there is a great difference between the information available on crane movements between the load profile recorded at 15 minute or at 1 minute/1 second intervals. In the urban environment further research is needed on a large sample of households to improve understanding of monitoring high resolution domestic energy consumption [24]. 


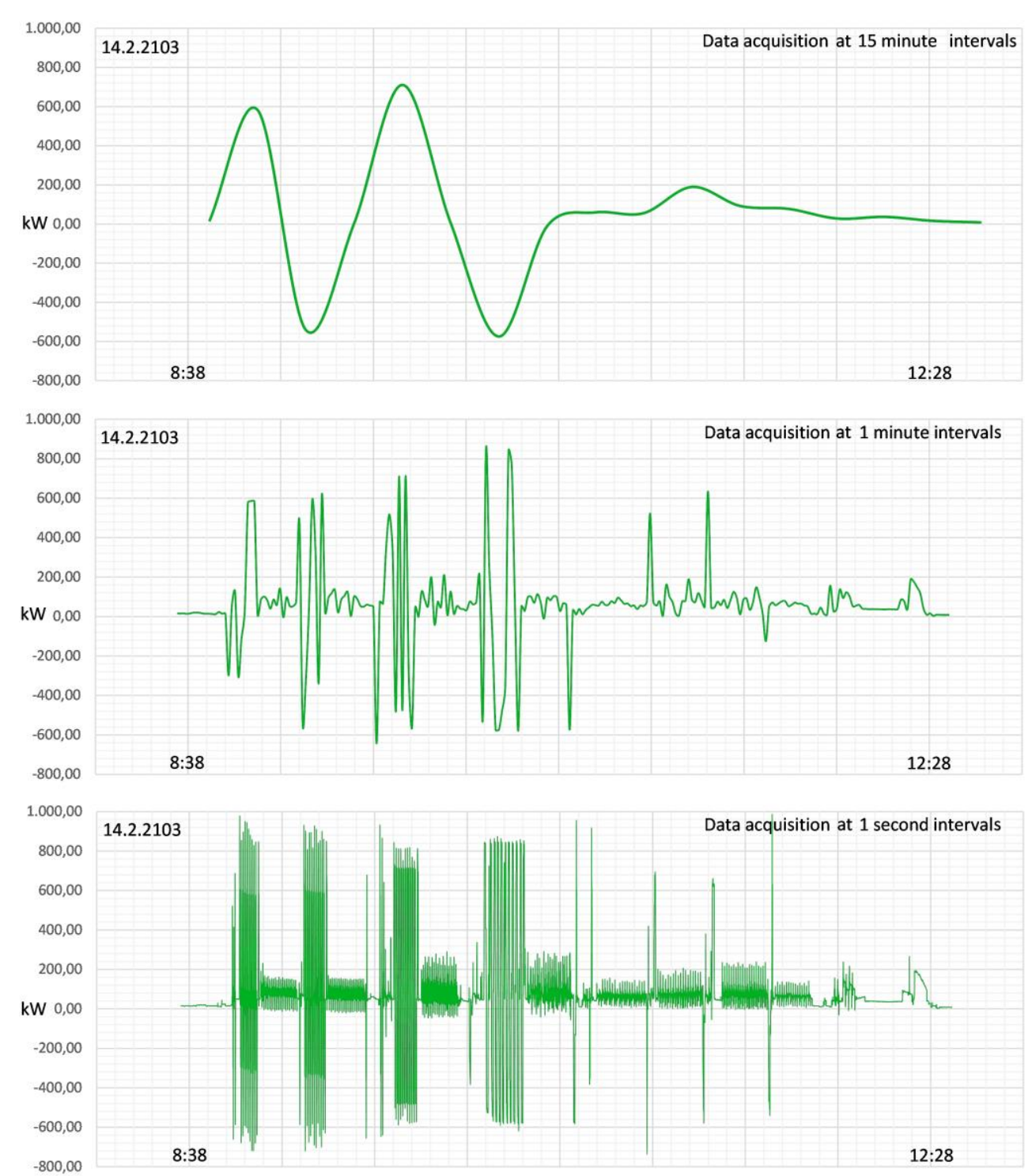

Figure 2. Container-handling gantry crane load profile at three different time intervals (15 minutes, 1 minute and 1 second)

The proposed concept aims to introduce a denser acquisition of consumption measurements from existing smart metering technologies during the validation phase and pilot runs. The main idea behind energy consumption pattern recognition is to analyse final energy consumption and break it down into its individual characteristic components, where the outcomes are available for immediate examination. During the learning cycle, a 1 minute interval is expected to fulfil the pattern recognition demands to extract the behaviour patterns and consumption of individual machines in an industrial environment, or appliances in the case of household consumption. A 15 minute interval is expected to be sufficient for analysis and recognition of energy consumption patterns when the pattern recognition algorithms are fully developed.

Energy consumption or load pattern recognition is directly linked to research in demand forecasting and finding the optimal combination of local power generation systems. The techniques adopted for load forecasting can be classified into model-based techniques, rule-based systems and non-linear neural learning systems. Expert systems and neural learning techniques are also identified as data mining applications or knowledge discovery from databases. Model-based techniques represent the classical 
approach, where curve-fitting procedures, linear regression, multiplicative autoregressive models and state-space models have been mainly used due to their transparency where the end-user is able to examine its operational behaviour. Rule-based systems have primarily focused on short term forecasting [25-27].

The availability of accurate and reliable data carries the potential to transform demand forecasting and detection of consumption patterns from a passive historical data-based activity to an active real-time data-driven process. In order to regulate a real-time environment, it is necessary to consider meter readings as a data stream. Pattern discovery from a data stream introduces dynamics that is not adequately addressed by conventional data mining techniques. High volume, data transience and rigid ordering of data are the key constraints in a smart meter data stream environment. This raises two challenges. Firstly, the issues surrounding consumption analysis, i.e. the pattern discovery algorithm, should be able to identify and distinguish between cyclic and non-repeating patterns, and secondly, the complexities introduced by the availability of meter readings in a real-time data stream environment. One of the possibilities is to use an Incremental Pattern Characterization Learning (IPCL) algorithm, which is able to incrementally characterize patterns in energy consumption. This also features incremental knowledge accumulation that maintains a layer of summarized representations of patterns characterized from each phase and associates this layer with new learning [26]. Other possibilities include the use of a multi-layer artificial neural network based on a BP algorithm or more sophisticated genetic algorithms and RBF Neural Networks [28].

\section{Context sensitive processing and contextualized consumption feedback}

The main objective of context-sensitive processing is to detect consumption patterns and enrich consumption data with the context in which the energy consumption actually occurred. As the context integrates different knowledge sources and binds knowledge to the user to guarantee that the understanding is consistent, context modelling is extensively investigated within knowledge management research. According to [11], a smart network with smart technology calls for a smart organization: both smart technology and a smart organization are needed to increase the intelligence of the energy network.

In the case of energy consumption in the industrial sector, the notion of context refers to (actual) characteristics of the industrial company, its production process, machinery and devices, whereas in the public sector the notion of context refers to the type of operation in the building and what follows from its function. The most common approaches to context-modelling are key-value models, Markup Scheme Models, Graphical Models such as UML, OOM, Logic Based Models and Ontology-Based Models. Present research on context modelling is mostly focused on ontologies [29]. Ontologies allow context-modelling at a semantic level, establishing a common understanding of terms and enabling context sharing, reasoning and reuse. It should be emphasized that application of context awareness for processing of energy consumption in households and the public sector has not yet been sufficiently exploited, and much research and development is needed to before they are mature for utility application.

The key research issue is the development of strategies for identifying long term energy use patterns on the one hand and identifying critical energy use patterns on the other, representing excessive energy consumption in relation to context changes, from the measured energy consumption and context data. This process enables the contextualization of consumption feedback. The main role of consumption feedback is to make energy consumption visible to the end-user. Contextualized feedback provides an 
opportunity to offer end-users more direct, detailed, comparable and comprehensive information about their energy consumption pattern and has the potential to influence their reasoning process and change their energy-related behaviour. End-users may sometimes make decisions based on the beliefs and values they perceive to be prevalent in their culture instead of on their personal beliefs and values [30]. This interaction can also help to bridge the gap between the end-user and the Smart Grids community.

Indirect or direct consumption feedback can be provided to consumers utilizing Smart Metering and its services. According to [31], indirect feedback is more suitable for demonstrating longer term effects on energy consumption as the consequence of behavioural changes and applied energy efficiency measures. Through indirect feedback the end-user has no direct access to the real-time consumption data and therefore responds to previous consumption behaviour and has to rely on processed information. These types of feedback are based on smart meter readings with a combination of appropriate and tailor-made energy efficiency indicators, disaggregated consumption data, detailed energy reports and other forms of presenting energy consumption patterns.

The main characteristic off direct feedback is that end-users have an immediate and easily accessible display of real-time energy consumption. A smart meter provides clear, concise and understandable information or a point of reference for improved feedback, preferably in combination with a separate in-house display (IHD) and individual appliance/device consumption metering. Direct feedback is more suitable for industrial end-users, but recent developments in domestic communications provide new paths for the data and destinations creating a Home Automation Network (HAN). This area is showing the greatest growth as developers recognize the opportunities presented by major national smart meter roll outs and develop links to meter vendors and energy suppliers. There are indications that consumers with a high energy use may respond more to direct feedback than consumers with a low energy use, because direct displays best show up the significance of moment-to-moment behaviour [31].

The proposed concept focuses on bringing together the benefits of direct and indirect feedback with the aim of stimulating conscious decision making and development of new energy efficient habits. Proposed feedback should be based on actual consumption, given frequently over longer period of time, involve interaction and choice for household, give information on energy consumption for specific appliances. It is envisioned that feedback should give information about individual performance relative to performance of others (comparative feedback) to activate social norms for energy efficiency. The platform will be designed to compile the acquired data and present the real-time consumption data in accordance to end-user behaviour pattern (context in which the consumption occurred). Also, intelligent consumption feedback should play a crucial role in introducing new utility services to end-users, i.e. facilitate the smooth transition of end-users to the dynamic tariff system and DSM [32].

\section{Decision support services}

Future energy utilities are likely to be focused on smaller distributed energy sources, a growth in RES, eliminating overloads, and reducing peak demand through optimised demand response options. Dynamic tariffs, time of use, and other pricing alternatives are under consideration to reduce electricity network congestion and energy costs. With these changes, the need to more effectively plan, engineer, and manage the distribution network is a critical requirement. Implementation of these activities is supported through advanced distribution management systems (DMS). Demand response is a key function that drives utilities to smart grid programmes and to the implementation of advanced DMS software. Some demand response actions depend on customers reacting on their 
own which implies a correlation between advanced DMS and contextualized consumption feedback. Regulators can also create rate structures that encourage similar conduct through normal attention to energy costs. However, since these approaches do not result in sufficient reduction, additional demand response options are provided, and advanced DMS can support decisions in prioritizing application of these options. The difficulty consists in finding similar interests among consumer groups (communities with similar goals) [33]. In the case of households, at least $30 \%$ of the population must participate in the demand response scheme to assure reliability and achieve a $20 \%$ peak reduction [34].

The proposed concept brings the necessary understanding of end-user behaviour to harmonize interests between the utility and the consumer group with complementary energy profiles. Detailed end-user energy patterns provided by the proposed interactive platform could be seen as a "missing link" in the advanced DMS to support the utility in its quest to optimize the network performance. To capitalize on emerging advanced DMS systems, the proposed platform should also enable integration with other advanced solutions, especially with location intelligence and existing customer relationship management (CRM) solutions. This can aid utilities in making the right decisions in network planning and determination of the most cost-effective and profitable design and upgrade of the network. By understanding the interests of end-users and the condition in the network, the utility can design new business cases by providing advanced energy services and energy management to the selected group of end-users (i.e. providing and managing central heating and cooling, installation of PV, CHP or CCHP, etc., DSM on a set of selected appliances). According to [35], the detailed end-user consumption profile can be used to implement an evaluation model of projects that will develop all possible scenarios for a technical and financial solution in order to highlight the best configuration for the stakeholders (investors and users) who benefit from the CCHP project. The proposed concept would also give necessary support to using CTES combined with RES for cooling needs in the building sector. However, for further development of CTES, additional analysis of alternative systems for individual buildings, groups of similar buildings, or common typologies of buildings in the same area are required [36].

By activating such services, the utility can actively involve end-users in local balancing and constantly adapt its services according to changes in end-user energy profiles and behaviour. To bring all these together, the Smart Grid is already envisioned to be a large-scale cyber-physical system that can improve the efficiency, reliability, and robustness of power and energy grids by integrating advanced techniques from various disciplines such as power systems, control, communications, signal processing, and networking. Also, there is a need to deploy novel models and algorithms that can capture the heterogeneous nature of the Smart Grid which is typically composed of a variety of nodes such as micro-grids, smart meters, appliances, and others, each of which having different capabilities and objectives [37]. The proposed concept and its decision support system intends to build on these principles and introduce end-user behavioural parameters into the utility decision process. In this context, Game-Theory constitutes a robust framework that can address many of the utility network challenges targeted by the proposed platform and is expected to constitute a key analytical tool in the design of the future Smart Grid.

\section{RESULTS AND DISCUSSION, PRELIMINARY PROOF OF CONCEPT - AND PILOT TESTING}

The described concept in the early prototype phase was tested at two residential multi-dwelling buildings in Ljubljana, Slovenia. Both buildings were built during the 
1960s in the same neighbourhood, having the same shape and orientation and are connected to the district heating system of the City of Ljubljana. Also, neither of the buildings has been renovated and the structure of the occupants (ownership, number of occupants, age and education) in both buildings is very similar. The design of the consumption feedback experiment is given in Figure 3.

\section{Initial preparation}

Installation of individual heat metering devices in each dwelling - required by Slovenian and EU regulations

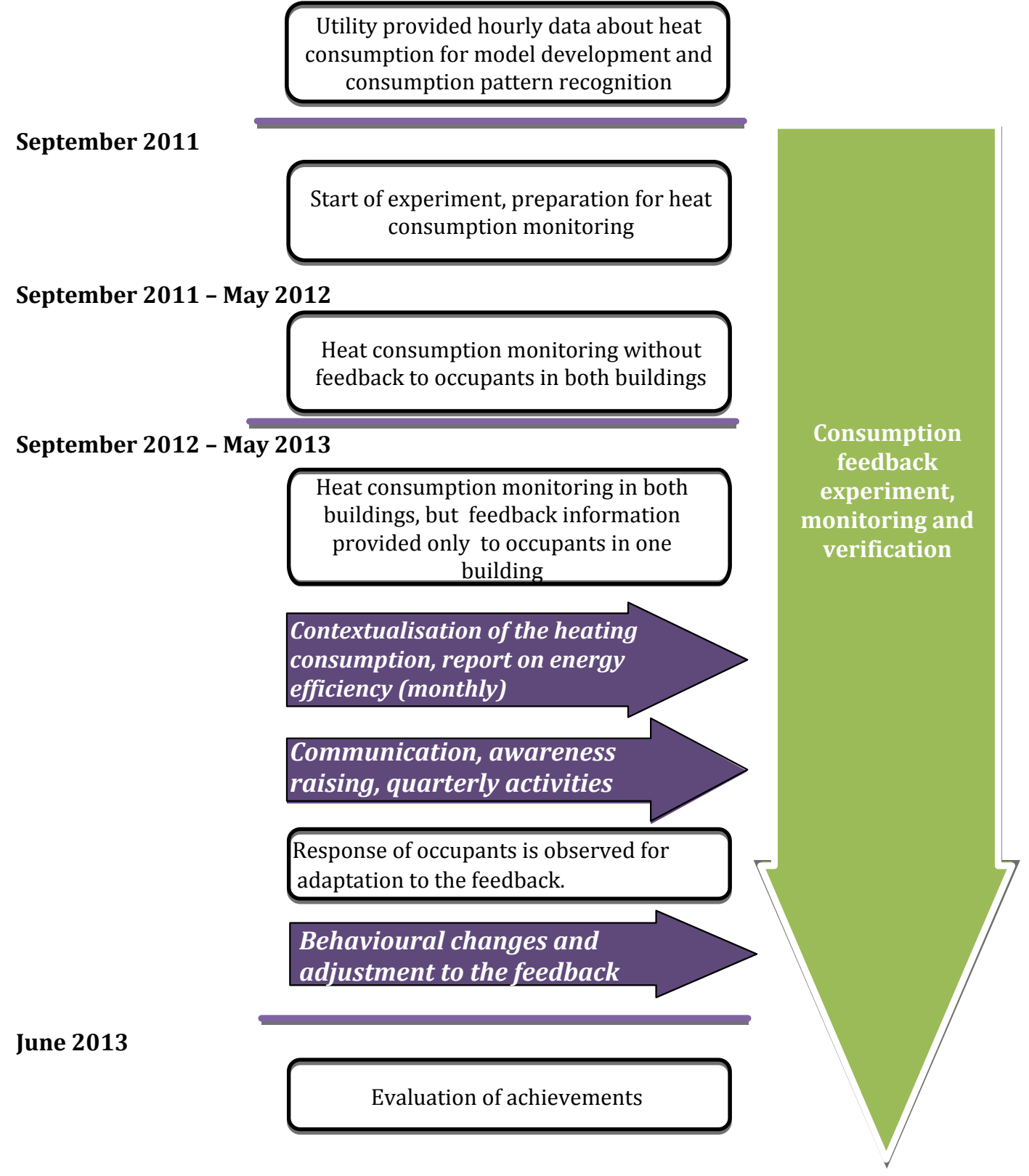

Figure 3. Design of the consumption feedback experiment

The trigger for the experiment was the installation of heat consumption metering devices in every dwelling in both buildings during the summer of 2011. The experiment actually started in September 2011 and heat consumption from the season 2010/11 was 
set as the reference consumption for results validation. During the heating season 2011/12 consumption in both buildings was monitored but no consumption feedback was provided. During the heating season 2012/13 once again consumption in both buildings was monitored but consumption feedback was provided only to the occupants of one building. Feedback on heat consumption was provided monthly to each dwelling individually. Dwelling occupants were informed about their performance relative to performance of other similar dwellings in the same building, Figure 4. Also, additional feedback on building level was available in a form of poster in building lobby.
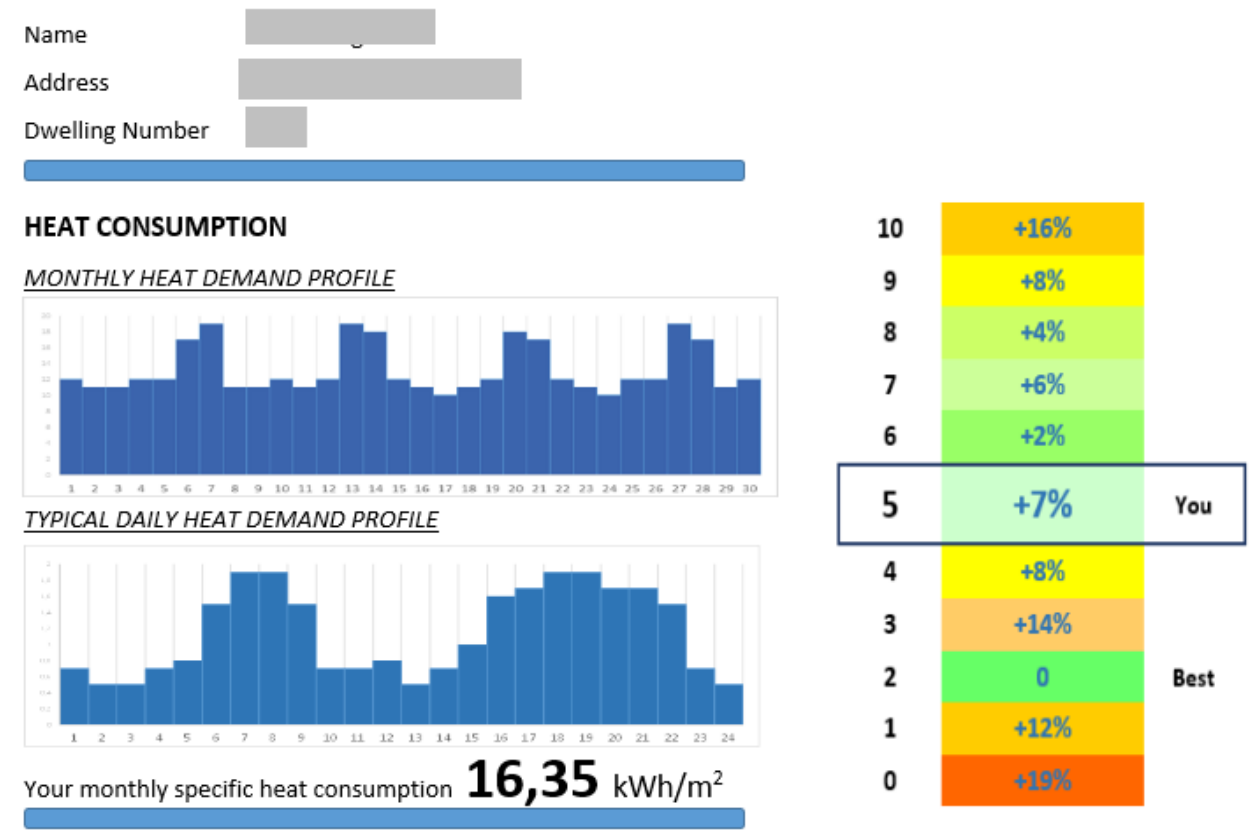

Figure 4. Design of the information provided to individual dwelling

The biggest challenge during the experiment was how to make consumption and billing data understandable to the occupants in the selected building. Quarterly meetings of building council were used to raise the awareness on energy efficiency and to describe efficiency indicators used in provided feedback. It was noticed that the occupants highly appreciated comparative feedback enriched with efficiency indicators and graphic representation of billing information compared to consumption in comparable past periods, to average consumption in the past year, and correlated to the inside and outside temperature difference. The results of the experiment are presented in Table 1; consumption feedback was provided to building 2 during the heating season 2012/13.

It is clear that individualisation of heat consumption positively influenced the energy performance of both buildings. In the case of building 2, customised consumption feedback provided occupants with new knowledge and additional savings were reached. The heat consumption data was processed, contextualised and well documented in order to be understandable to the occupants of building 2. Receiving regular information and updates on progress was very highly appreciated by the occupants.

However, one to be aware that before drawing any other conclusion the approach presented and additional analysis should be carried out for a large group of similar buildings. The complexity of the proposed interactive platform arises from the many variables that provide contextual information, including end-user behaviour during usual daily operations. Based on experiences from the pilot testing and before developing the 
full prototype it would be very important to gain objective empirical insight into how to adapt the prototype to specific demands of the end-users. Also, it is clear that additional research work must include experts from social sciences which would be responsible for the final development of user-centred design, and to deal with people's values and attitudes toward pro-environmental behaviour.

Table 1. Results of the consumption feedback experiment

\begin{tabular}{|c|c|c|c|c|c|c|}
\hline & \multicolumn{2}{|c|}{$\begin{array}{c}\text { Heating season } \\
2010 / 11\end{array}$} & \multicolumn{2}{|c|}{$\begin{array}{c}\text { Heating season } \\
2011 / 12\end{array}$} & \multicolumn{2}{|c|}{$\begin{array}{c}\text { Heating season } \\
2012 / 13\end{array}$} \\
\hline & $\begin{array}{c}\text { Building } 1 \\
\text { heat } \\
\text { consum. } \\
{[\mathrm{kWh}]}\end{array}$ & $\begin{array}{c}\text { Building } 2 \\
\text { heat } \\
\text { consum. } \\
{[\mathrm{kWh}]}\end{array}$ & $\begin{array}{c}\text { Building } 1 \\
\text { heat } \\
\text { consum. } \\
{[\mathrm{kWh}]}\end{array}$ & $\begin{array}{c}\text { Building } 2 \\
\text { heat } \\
\text { consum. } \\
{[\mathrm{kWh}]}\end{array}$ & $\begin{array}{c}\text { Building } 1 \\
\text { heat } \\
\text { consum. } \\
\text { [kWh] }\end{array}$ & $\begin{array}{c}\text { Building } 2 \\
\text { heat } \\
\text { consum. } \\
{[\mathrm{kWh}]}\end{array}$ \\
\hline September & 3,052 & 2,960 & 4,666 & 4,125 & 0 & 0 \\
\hline October & 40,904 & 41,531 & 25,210 & 24,812 & 35,315 & 34,680 \\
\hline November & 52,777 & 51,365 & 52,773 & 59,834 & 50,498 & 42,250 \\
\hline December & 99,283 & 101,008 & 89,057 & 87,710 & 74,339 & 55,340 \\
\hline January & 90,851 & 91,552 & 91,031 & 89,133 & 68,103 & 67,010 \\
\hline February & 84,483 & 80,646 & 79,070 & 79,332 & 70,133 & 66,690 \\
\hline March & 52,340 & 53,893 & 36,554 & 36,670 & 55,486 & 52,150 \\
\hline April & 27,714 & 24,301 & 11,188 & 10,141 & 36,454 & 32,540 \\
\hline May & 15,588 & 16,506 & 9,711 & 9,360 & 1,342 & 0 \\
\hline Total $[\mathrm{kWh}]$ & 466,991 & 463,763 & 399,259 & 401,117 & 391,670 & 350,660 \\
\hline $\begin{array}{l}\text { Heating degree } \\
\text { day }\end{array}$ & \multicolumn{2}{|c|}{2,862} & \multicolumn{2}{|c|}{2,954} & \multicolumn{2}{|c|}{2,899} \\
\hline $\begin{array}{c}\text { Corrected heat } \\
\text { consumption } \\
{[\mathrm{kWh}]}\end{array}$ & 466,991 & 463,763 & 386,824 & 388,625 & 386,671 & 346,185 \\
\hline $\begin{array}{c}\text { Specific heat } \\
\text { consumption } \\
{\left[\mathrm{kWh} / \mathrm{m}^{2}\right]}\end{array}$ & 123 & 122 & 102 & 102 & 102 & 91 \\
\hline $\begin{array}{c}\text { Heat } \\
\text { consumption } \\
\text { savings } \\
\text { compared to } \\
\text { reference in } \\
2010 / 11[\%]\end{array}$ & I & I & 17.2 & 16.2 & 17.2 & 25.4 \\
\hline
\end{tabular}

\section{CONCLUSION}

Conscious decisions and individual actions of end-users regarding their energy use will play a crucial role in the transition towards a low carbon and sustainable society. Implementation of technical solutions alone without the personal involvement of end-user will not be enough for future sustainable urban development. In this social aspect, energy utilities will play a major role on the energy market by promoting energy-efficient (environmentally relevant) behaviour and making energy-efficient choices more attractive.

This paper shows how energy utilities supported by expert systems can make it easier for customers to use energy more efficiently. The proposed concept goes beyond traditional energy management solutions and explores ways in which individual 
end-users can be included in information exchange flows and see their consumption in a proper context. The contextually informed end-user can consciously respond to everyday situations and can be encouraged to be more energy efficient. This includes coordination with other sectors and integration with other advanced distribution management system solutions, such as location intelligence and customer relationship management solutions. These existing solutions, combined with the real-time detection of individual energy consumption profiles from streamed consumption data and contextualization of these profiles can be used to build an intelligent consumption feedback platform for use by the utility. By incorporating all available data and the consumption feedback into the energy pattern recognition loop, the end-user response to feedback can be easily evaluated and employed by the utility in its optimization process. The proposed concept brings the necessary understanding of end-user behaviour to harmonize interests between the utility and a consumer group with complementary interests and energy profiles.

In this initial phase the proposed concept of an interactive platform for real time energy consumption analysis at the utility and consumer level seems to have much potential. The next step is to prove the viability of the concept by using smart meters together with a knowledge infrastructure (additional contextual information) to support decision making on demand side management and demand response services. However, additional analysis must be carried out for a large group of similar sites to obtain reliable proof of the proposed concept. Also, further research work should concentrate on how to uncover/reveal context in energy consumption in the complex urban and industrial environment and on the development of services for accurate determination of energy usage patterns.

\section{NOMENCLATURE}

\section{Abbreviations}

$\begin{array}{ll}\text { ANN } & \text { Artificial Neural Network } \\ \text { ASHP } & \text { Air Source Heat Pumps } \\ \text { BP } & \text { Back Propagation } \\ \text { CCHP } & \text { Combined Cooling, Heat and Power } \\ \text { CHP } & \text { Combined Heat and Power } \\ \text { CRM } & \text { Customer Relationship Management } \\ \text { CTES } & \text { Cool Thermal Energy Storage } \\ \text { DMS } & \text { Distribution Management Systems } \\ \text { DRS } & \text { Demand Response Services } \\ \text { DSM } & \text { Demand Side Management } \\ \text { HAN } & \text { Home Automation Network } \\ \text { ICT } & \text { Information and Communication Technologies } \\ \text { IHD } & \text { In House Display } \\ \text { IPCL } & \text { Incremental Pattern Characterization Learning } \\ \text { OOM } & \text { Object Oriented Modelling } \\ \text { PV } & \text { Photovoltaic } \\ \text { RBF } & \text { Radial Basis Function } \\ \text { RES } & \text { Renewable Energy Sources } \\ \text { UML } & \text { Unified Modelling Language }\end{array}$

\section{REFERENCES}

1. Verbong, G. P. J., Beemsterboer, S., Sengers, F., Smart Grids or Smart Users? Involving Users in developing a Low Carbon Electricity Economy, Energy Policy, Vol. 52, pp 117-125, 2013, http://dx.doi.org/10.1016/j.enpol.2012.05.003 
2. Geelen, D., Reinders, A., Keyson, D., Empowering the End-user in Smart Grids: Recommendations for the Design of Products and Services, Energy Policy, Vol. 61, pp 151-161, 2013, http://dx.doi.org/10.1016/j.enpol.2013.05.107

3. Kanellakis, M., Martinopoulos, G., Zachariadis, T., European Energy Policy - A Review, Energy Policy, Vol. 62, pp 1020-1030, 2013, http://dx.doi.org/10.1016/j.enpol.2013.08.008

4. Helm D., The European Framework for Energy and Climate Policies, Energy Policy, Vol. 64, pp 29-35, 2014, http://dx.doi.org/10.1016/j.enpol.2013.05.063

5. Gram-Hanssen, K., Efficient Technologies or User Behaviour, which is the more Important when Reducing Households' Energy Consumption?, Energy Efficiency Vol. 6, No. 3, pp 447-457, 2013.

6. Matthies, E., Wie können PsychologInnen ihr Wissen besser an die PraktikerIn bringen? Vorschlag eines neuen, integrativen Einflussschemas umweltgerechten Alltagshandelns., Umweltpsychologie, Vol. 9, No. 1, pp 62-81, 2005.

7. Fischer, C., Feedback on Household Electricity Consumption: A Tool for saving Energy?, Energy Efficiency, Vol. 1, No. 1, pp 79-104, 2008.

8. Ćosić, B., Krajačić, G., Duić, N., A 100\% Renewable Energy System in the year 2050: The Case of Macedonia, Energy, Vol. 48, No. 1, pp 80-87, 2012, http://dx.doi.org/10.1016/j.energy.2012.06.078

9. Milan, C., Bojesen, C., Nielsen, M. P., A Cost optimization Model for $100 \%$ Renewable Residential Energy Supply Systems, Energy, Vol. 48, No. 1, pp 118-127, 2012, http://dx.doi.org/10.1016/j.energy.2012.05.034

10. Blumsack, S. and Fernandez, A., Ready or not, here comes the Smart Grid!, Energy, Vol. 37, No. 1, pp 61-68, 2012, http://dx.doi.org/10.1016/j.energy.2011.07.054

11. Lund, H., Andersen, A. N., Østergaard, P. A., Vad Mathiesen, B., Connolly, D., From Electricity Smart Grids to Smart Energy Systems - A Market Operation based Approach and Understanding, Energy, Vol. 42, No. 1, pp 96-102, 2012, http://dx.doi.org/10.1016/j.energy.2012.04.003

12. Palander, T., Modelling Renewable Supply Chain for Electricity Generation with Forest, Fossil, and Wood-waste Fuels, Energy, Vol. 36, No. 10, pp 5984-5993, 2011, http://dx.doi.org/10.1016/j.energy.2011.08.017

13. Michalena, E. and Hills, J. M., Renewable Energy Issues and implementation of European Energy Policy: The missing Generation?, Energy Policy, Vol. 45, pp 201-216, 2012, http://dx.doi.org/10.1016/j.enpol.2012.02.021

14. Arends, M. and Hendriks, P. H. J., Smart Grids, Smart Network Companies, Utilities Policy, Vol. 28, pp 1-11, 2014, http://dx.doi.org/10.1016/j.jup.2013.10.003

15. Niemi, R., Mikkola, J., Lund, P. D., Urban Energy Systems with Smart Multi-carrier Energy Networks and Renewable Energy Generation, Renewable Energy, Vol. 48, pp 524-536, 2012, http://dx.doi.org/10.1016/j.renene.2012.05.017

16. Giordano, V. and Fulli, G., A Business Case for Smart Grid Technologies: A Systemic Perspective, Energy Policy, Vol. 40, pp 252-259, 2012, http://dx.doi.org/10.1016/j.enpol.2011.09.066

17. Sechilariu, M., Wang, B., Locment, F., Building-integrated Microgrid: Advanced Local Energy Management for Forthcoming Smart Power Grid Communication, Energy and Buildings, Vol. 59, pp 236-243, 2013, http://dx.doi.org/10.1016/j.enbuild.2012.12.039

18. Xue, X., Wang, S., Sun, Y., Xiao, F., An Interactive Building Power demand Management Strategy for Facilitating Smart Grid Optimization, Applied Energy, Vol. 116, pp 297-310, 2014, http://dx.doi.org/10.1016/j.apenergy.2013.11.064

19. European Smart Metering Alliance, ESMA 2009 annual report on the progress in smart metering, 
http://eaci-projects.eu/iee/page/Page.jsp?op=project_detail\&prid=1564\&side=down loadablefiles, [Accessed: 17-May-2013]

20. Kavousiana, A., Rajagopala, R., Fischera, M., Determinants of Residential Electricity Consumption: Using Smart Meter Data to examine the Effect of Climate, Building Characteristics, Appliance Stock, and Occupants' Behavior, Energy, Vol. 55, pp 184-194, 2013, http://dx.doi.org/10.1016/j.energy.2013.03.086

21. Markowitz, E. M. and Malle, B. F., Did you see that? Making Sense of Environmentally Relevant Behavior, Ecopsychology, Vol. 4, pp 37-50, 2012.

22. Gangale, F., Mengolini, A., Onyeji, I.,Consumer engagement: An Insight from Smart Grid Projects in Europe, Energy Policy, Vol. 60, pp 621-628, 2013, http://dx.doi.org/10.1016/j.enpol.2013.05.031

23. Ancillotti, E., Bruno, R., Conti, M., Review: The role of Communication Systems in Smart Grids: Architectures, Technical Solutions and Research Challenges, Computer Communications, Vol. 36, No. 17-18, pp 1665-1697, 2013, http://dx.doi.org/10.1016/j.comcom.2013.09.004

24. Gelazanskas, L. and Gamage, K. A. A., Demand Side Management in Smart Grid: A Review and Proposals for Future Direction, Sustainable Cities and Society, Vol. 11, pp 22-30, 2014, http://dx.doi.org/10.1016/j.scs.2013.11.001

25. Ihbal, A. M., Rajamani, H. S., Abd-Alhameed, R. A., Jalboub, M. K., Identifying the Nature of Domestic Load Profile from a single Household Electricity Consumption Measurements, Systems, Signals and Devices (SSD), 2011 8th International Multi-Conference Proceedings, pp 1-4, March 22-25, 2011.

26. Akselrad, D., Petcu, V., Romer, B., Schmid, A., Bytschkow, D., Engelken, M., Making Home Energy usage transparent for Households using Smart Meters, 2011 IEEE International Conference on Consumer Electronics - Berlin (ICCE-Berlin), pp 150-153, September 6-8, 2011.

27. De Silva, D., Xinghuo, Y., Alahakoon, D., Holmes, G., Incremental Pattern Characterization learning and forecasting for Electricity Consumption using Smart Meters, 2011 IEEE International Symposium on Industrial Electronics (ISIE), pp 807-812, June 27-30, 2011.

28. Qing-wei, Z., Zhi-Hai, X., Jian, W., Prediction of Electricity Consumption based on Genetic Algorithm - RBF Neural Network, 2010 2nd International Conference on Advanced Computer Control (ICACC), Vol.5, pp 339-342, March 27-29, 2010.

29. Sattanathan, S., Narendra, N. C., Maamar, Z., Ontologies for Specifying and reconciling Contexts of Web Services, Electronic Notes in Theoretical Computer Science, Vol. 146, No. 1, pp 43-57, 2006.

30. Chiu, C. Y., Gelfand, M. J., Yamagishi, T., Shteynberg, G., Wan, C., Intersubjective Culture: The Role of Intersubjective Perceptions in Cross-Cultural Research, Perspectives on Psychological Science, Vol. 5, No. 4, pp 482-493, 2010.

31. Environmental Change Institute, The effectiveness of feedback on Energy Consumption, A Review for DEFRA of the Literature on metering, billing and Direct Displays, http://www.eci.ox.ac.uk/research/energy/downloads/smart-metering-report.pdf, [Accessed: 18-June-2013]

32. Cooper, S. J. G., Dowsett, J., Hammond, G. P., McManus, M. C., Rogers, J. G., Potential of Demand Side Management to Reduce Carbon Dioxide Emissions Associated with the Operation of Heat Pumps, J. sustain. dev. energy water environ. syst., Vol. 1, No. 2, pp 94-108, 2013, http://dx.doi.org/10.13044/j.sdewes.2013.01.0007 
33. Ciuciu, I. G., Meersman, R., Dillon, T., Social Network of Smart-metered Homes and SMEs for Grid-based Renewable Energy Exchange, 6th IEEE International Conference on Digital Ecosystems Technologies (DEST), pp 1-6, June 18-20, 2012.

34. Dave, S., Sooriyabandara, M., Yearworth, M., System Behaviour modelling for Demand Response Provision in a Smart Grid, Energy Policy, Vol. 61, pp 172-181, 2013, http://dx.doi.org/10.1016/j.enpol.2013.05.098

35. Di Palma, D., Lucentini, M., Rottenberg, F., Trigeneration Plants in Italian Large Retail Sector: A Calculation Model for the TPF Projects with Evaluation of all the Incentivizing Mechanisms, J. sustain. dev. energy water environ. syst., Vol. 1, No. 4, pp 375-389, 2013, http://dx.doi.org/10.13044/j.sdewes.2013.01.0028

36. Ban, M., Krajačić, G., Grozde, M., Ćurko, T., Duić N., The Role of Cool Thermal Energy Storage (CTES) in the Integration of Renewable Energy Sources (RES) and Peak Load Reduction, Energy, Vol. 48, No. 1, pp 108-117, 2012, http://dx.doi.org/10.1016/j.energy.2012.06.070

37. Saad, W., Han, Z., Poor, H. V., Basar, T., Game-Theoretic Methods for the Smart Grid: An Overview of Microgrid Systems, Demand-Side Management, and Smart Grid Communications, Signal Processing Magazine, IEEE, Vol. 29, No. 5, pp 86-105, 2012. 